Industrial Engineering

\& Management Systems

Vol 12, No 4, December 2013, pp.305-305

http://dx.doi.org/10.7232/iems.2013.12.4.305

ISSN 1598-7248 | EISSN 2234-6473 |

(C) 2013 KIIE

\title{
Foreword: Special Issue on Mathematical Modeling and Applications of Operations Research
}

\author{
Huynh Trung Luong* \\ Asian Institute of Technology, Pathumthani, Thailand \\ * Corresponding Author, E-mail: luong@ait.ac.th
}

The Asia Pacific Industrial Engineering and Management Systems (APIEMS) Conferences are annual conferences organized by the Asia Pacific Industrial Engineering and Management Society. The core value of APIEMS is associating and exchanging the better industrial engineering education, researches, and exchange information from different countries. Since the first APIEMS conference organized in 1998 in Beijing, China, APIEMS has rapidly emerged as an important forum for exchange of ideas and information about latest developments in the field of industrial engineering and management system among professionals from Asia-Pacific countries.

The 13th Asia Pacific Industrial Engineering and Management Systems Conference (APIEMS2012) was held on December 2-5, 2012 in Phuket City, the capital of the biggest island located in the Andaman Sea of southern Thailand which is also a very famous touristical city. The conference, which covers a wide range of topics in response to the conference theme of "Achieving Sustainability through Effective Resource Management", successfully provided a forum for researchers, university lecturers and engineers to communicate on their latest achievements in the field of industrial engineering and management systems and to seek for future collaboration.

In this special issue of the Industrial Engineering and Management Systems Journal (IEMS), six papers were selected among more than 250 submitted papers to the conference after a usual reviewing process in accordance with the rigorous standards of the journal.

The first paper by Chamnanlor et al. deals with the reentrant flow shop scheduling problem with time windows constraint for hard disk manufacturing. A hybrid genetic algorithm is developed for solution purpose. The second paper by Parwananta et al. proposes a mathematical model for determining optimal operation of a green supply chain in consideration of used products collection incentive and quality in reuse of used products. Decision-makings under decentralized supply chain and under centralized supply chain as well as the effect of quality distribution of the used products on the optimal decisions are analyzed. The third paper by Tae and Kim proposes a feeder reassign improvement algorithm for a multi-head surface mount device in electronic industry. Numerical experiments are then conducted to show the efficiency of the newly proposed algorithm. In the fourth paper, Das et al. proposes a mathematical modeling based approach for assessing disaster effects and selecting suitable mitigation alternatives after a disaster event. A numerical example is given to illustrate the applicability of the proposed model in disaster mitigation planning. In the fifth paper, Tanaka develop a multiobjective model to describe the tradeoffs involved when locating drop-off points for collecting used products and transporting them to designated locations. In this paper, three objectives are considered, namely, maximization of used products collected at drop-off points, minimization of the transportation cost of collected products, and minimization of fixed cost of locating drop-off points. Last but not least, Mai Ha et al. suggests a method for estimating the expected value and the standard deviation of the container handling cycle time of the advanced quay cranes that involve several handling components moving at the same time. The accuracy of the proposed estimation method is then evaluated through comparison with simulation results.

As the guest editor for this special issue, I would like to thank the authors for their contributions and the reviewers for their time that helped improve the quality of this issue. I would like to specially thank the editor-in-chief of IEMS, Prof. Mitsuo Gen, for giving me the opportunity to publish selected papers as a special issue of the journal. I would also like to thank the managing editor, Prof. Chi-Hyuck Jun, for guiding me through the editorial process. It was a pleasure to take part in this special issue for IEMS. 